\title{
GROUNDED THEORY SEBAGAI PILIHAN METODE RISET KUALITATIF KEPERAWATAN
}

\author{
Setyowati $^{1 *}$ \\ 1. Keperawatan Maternitas Fakultas Ilmu Keperawatan Universitas Indonesia, Depok 16424, Indonesia \\ *Email: watisetyowati@yahoo.com.au
}

\begin{abstract}
Abstrak
Grounded theory merupakan metode riset kualitatif yang menggunakan suatu set prosedur yang sistematik untuk mengembangkan suatu teori secara induktif tentang suatu fenomena. Metode ini dimulai dari suatu pernyataan yang masih kabur dan akhirnya menghasilkan teori yang dikumpulkan dari berbagai data. Grounded theory membuat kenyataan bahwa kesenjangan antara teori dan praktik dapat diatasi, sehingga dapat diaplikasikan dalam praktik dan meningkatkan pelayanan. Analisis data dilakukan melalui empat tahap. Pendekatan grounded theory sangat membantu perawat untuk memahami perilaku sosial agar perawat lebih mengerti dan memahami pasiennya.
\end{abstract}

Kata kunci: analisis data, grounded theory, keperawatan, metode kualitatif

\section{Abstract}

Grounded theory is a qualitative research method utilizing a set of systematic procedure to develop an inductive theory on a particular phenomenon. It is initiated by answering a vague question and eventually generating theory from the data collected. The data analysis is carried out in 4 stages in the grounded theory approach. Grounded theory may bridge the gap between theory and practice. It can be applied into practice to enhance the quality of nursing service. This approach helps nurses to understand the social behaviour of the patients.

Key words: data analysis, grounded theory, nursing, qualitative method

\section{Pendahuluan}

Perkembangan ilmu dan teknologi yang pesat dan diikuti dengan semakin kompleksnya kebutuhan masyarakat dalam berbagai bidang. Hal ini menyebabkan para ahli berusaha mengembangkan ilmunya melalui riset atau penelitian. Untuk itu, berbagai metode dikembangkan agar menghasilkan hasil riset yang lebih lengkap dan valid, diantaranya dengan metode kualitatif. Metode ini lebih menggali hal-hal yang berupa perilaku dan pengalaman manusia untuk fenomena yang diteliti, salah satunya yaitu grounded theory.

Grounded theory ditemukan oleh dua sosiolog Glaser dan Strauss, dalam riset bersama tentang pasien yang meninggal dunia di rumah sakit. Kedua sosiolog ini kemudian mengembangkan suatu metode riset kualitatif yang dikenal sebagai 'Grounded theory' (Glaser \& Strauss, 1967).
Grounded theory merupakan suatu metode kualitatif yang menggunakan suatu set prosedur yang sistematik untuk mengembangkan suatu teori secara induktif tentang suatu fenomena. Di dalam hubungan antara pertanyaan riset dan metode riset, maka grounded theory dimulai dari suatu pertanyaan yang masih kabur dan akhirnya menghasilkan teori yang dikumpulkan dari berbagai data. Dengan demikian, pendekatan ini bukan untuk mengidentifikasi dan membuktikan suatu hipotesis.

Pendekatan grounded theory sangat membantu perawat untuk memahami perilaku sosial sehingga perawat lebih mengerti dan memahami pasiennya. Grounded Theory merupakan pilihan jika metode lain tidak dapat digunakan, terutama dalam bidang dengan variabel dependen yang sensitif, seperti kesehatan, bisnis, dan manajemen (Glaser, 1995). Tulisan ini akan menggambarkan secara singkat tentang metode riset kualitatif yang kompleks yaitu grounded theory. 


\section{Pengertian}

Grounded theory (selanjutnya disingkat GT) merupakan suatu metodekualitatif untuk menghasilkan pengembangan teori baik dengan pendekatan induktif dan deduktif. Tujuan GT adalah menghasilkan hipotesis berdasarkan ide konseptual. Metode riset kualitatif ini dapat dijelaskan baik dalam riset kualitatif maupun kuantitatif.

Penggunaan GT terampuh ialah pada investigasi halhal yang masih belum jelas atau untuk memperoleh persepsi baru dari situasi sudah yang lumrah (Glaser, 1995). Grounded theory adalah teori yang berasal dari kenyataan dan menjelaskan kejadian yang ada (Field \& Morse, 1985). GT membuat seorang perawat dapat mengeksplorasi data yang banyak ditemukan (Stein 1985) dan membuat perawat lebih memahami apa yang terjadi. GT membuat kenyataan bahwa kesenjangan antara teori dan praktik dapat diatasi, sehingga dapat diaplikasikan dalam praktik dan meningkatkan pelayanan.

Tujuan metode GT adalah untuk menilai efek dari perilaku sosial. Perbedaannya dengan riset etnografi yaitu etnografi mengungkapkan suatu pertanyaan mengapa seseorang berpikir apa yang dia lakukan dan mengapa hal itu dilakukan. Sedangkan pendekatan fenomenologiberupaya menilai bagaimana seseorang menceritakan pengalamannya (Thorne, 1991).

Grounded theory membuat peneliti dapat menemukan kerangka konsep yang menjelaskan skenario dari riset (Stein, 1985). Setiap pendekatan GT memiliki tiga elemen dasar (Legewie \& Schervier-Legewie, 2004) yang harus dipenuhi di antaranya theoretical sensitive coding, yaitu mengembangkan konsep teori dari data yang menjelaskan tentang fenomena yang diteliti. Elemen kedua adalah theoretical sampling yaitu menetapkan siapa yang diwawancara dan apa yang diobservasi selanjutnya untuk membentuk teori. Hal itu dilakukan dengan memulai analisis pada waktu pertama melakukan wawancara. Selanjutnya, pendekatan GT mempunyai kebutuhan untuk membandingkan antara fenomena dan konteks yang diteliti sehingga memperkuat teori yang dibentuk.
Jadi Grounded Theory adalah metode kualitatif yang ditujukan untuk menghasilkan atau mengembangkan suatu teori atau konsep yang berasal dari kenyataan dan menjelaskan kejadian yang ada dengan menilai efek dari perilaku sosial dari fenomena yang diteliti. Hasil dari GT di keperawatan merupakan konsepkonsep baru berdasarkan kejadian nyata dalam praktik keperawatan dan hasil tersebut dapat diterapkan dalam praktik keperawatan.

\section{Prinsip-Prinsip Grounded Theory}

Pendekatan GT harus menggunakan prinsip sebagai berikut:

1. Tujuan pendekatan data tanpa kerangka yang pasti, tetapi dengan melihat hal-hal yang belum pasti. Secara teoritis, GT tidak sejalan dengan pengembangan pengetahuan secara idealistik (yaitu menentukan kerangka konsep yang jelas kemudian membuktikan hipotesis atau teori yang ada dalam praktik melalui riset), tetapi GT menghasilkan teori atau konsep pada fenomena yang diteliti setelah mengumpulkan data-data yang diperlukan. Hal ini menolak pendapat bahwa ilmu pengetahuan ditemukan dan tidak dapat dibantah dengan aturanaturan tertentu.

2. Tujuan pengembangan teori dikembangkan sedekat mungkin dengan keadaan nyata, aplikasi dasar, dan pengalaman nyata. Teori dibentuk dari data yang dihasilkan. Teori digeneralisasikan dengan karakteristik tertentu dengan menekankan pada proses.

\section{Grounded Theory dalam Keperawatan}

Keperawatan adalah disiplin praktik klinik dan sering dijelaskan sebagai ilmu dan seni. Oleh sebab itu, sesuai dengan epistemologinya, riset dari ilmu keperawatan harus meliputi intuisi dari pengalaman perawat yang dibentuk menjadi riset empiris secara sistematis untuk mengidentifikasi ruang lingkup ilmu keperawatan (Schultz \& Meleis ,1988).

Pendekatan GT memungkinkan perawat untuk mengidentifikasi, menjelaskan, serta melakukan generalisasi yang akan membentuk substansi dari teori. 
Dengan hasil riset GT maka perawat dapat menerapkannya pada petunjuk kerja dalam praktik keperawatan. Tanpa mengurangi kegunaannya, teori inibiasanya diaplikasikan pada konteks individu pasien, individu perawat, dan setting individual (Thomas \& James, 2006). Pendekatan GT sangat membantu perawat untuk memahami perilaku sosial sehingga mereka lebih mengerti dan memahami pasiennya.

Teori dari 'symbolic interactionism' menggarisbawahi grounded theory (Chenitz \& Swanson, 1986). Symbolic interactionism berfokus pada arti suatu kejadian pada seseorang dalam tatanan alamiah. Dengan demikian, perawat dapat melihat arti dari asuhan keperawatan yang dilakukannya pada pasien apakah telah memenuhi kebutuhan pasien yang sebenarnya. Ide sentral dari menggeneralisasi teori dengan pendekatan ini adalah bahwa teori ini digeneralisasikan dari data dengan tidak menggunakan hipotesis sebelumnya (Burawoy, 1991).

\section{Analisis Data}

Semua data adalah sumber utama/ fundamental dari GT yang berarti semua hal yang dilakukan oleh peneliti pada area tertentu. Sumber data tidak hanya wawancara atau observasi tetapi semua data yang dapat membantu peneliti menggeneralisasikan konsepkonsep untuk menjadikan suatu teori. Data didapat dari catatan lapangan yang berasal dari wawancara informal, pengajaran, seminar, pertemuan dengan kelompok, artikel darimajalah, internet, juga tayangan televisi, pembicaraan dengan teman, dan lain-lain. Hal ini juga dimungkinkan bagi peneliti yang memiliki pengetahuan yang baik di area yang diteliti untuk mewawancara dirinya sendiri serta mengolah data tersebut seperti data lainnya.

Data dari hasil wawancara tidak terstruktur kemudian dioleh dengan cara yang sama dengan data hasil observasi dan refleksi diri. Chenitz dan Swanson (1986) menjelaskan wawancara tidak terstruktur sebagai suatu 'conversation with a purpose'. Rekaman hasil wawancara harus ditulis atau 'transcribed' dan dilakukan pengkodean untuk kalimat, kata, dan komentar yang merupakan kata kunci. Kemudian dibuat tema dan kode lagi. Selanjutnya kode dipilih menjadi kategori dan difokuskan pada kategori untuk dirumuskan menjadi teori pada area yang diteliti. Ada empat tahap dari cara analisis data dalam GT setelah melakukan tranksrip dan mengumpulkan data, antara lain (Glaser, 1992):

1. Tahap pengkodean/ 'Open Coding', tujuannya untuk mengidentifikasi kata kunci dari semua data yang dikumpulkan

2. Tahap pembentukan konsep/'Axial Coding'dengan tujuan untuk mengumpulkan kode-kode yang sama isinya yang memungkinkan data dikelompokkan menjadi kategori yang saling berhubungan dan terbentuk konsep-konsep

3. Tahap kategorisasi/ 'Selective Coding' dengan tujuan mengelompokkan konsep yang dibentuk kemudian dipilih yang ada hubungannya dengan pembentukan teori untuk masalah riset.

4. Tahap pembentukan teori ditujukan untuk menjelaskan subjek yang diteliti dengan memperkuat dengan teori-teori yang sudah ada dan studi literatur. Tahap ini sering disebut 'theoretical note'.

Urutan dari analisis data sebagaimana digambarkan dalam skema 1 yaitu dimulai dari mengumpulkan data dengan kemungkinan melakukan interpretasi dan analisis pada waktu mengumpulkan data, dilanjutkan pada tahap analisis data. Kemudian, diteruskan dengan pembentukan konsep, dimulai tahap pertama pemberian kode pada substansi. Setelah ditemukan kata kunci yang saling berhubungan, maka dihasilkan kategori-kategori. Kategori yang berhubungan akan menghasilkan konsep. Tahap selanjutnya dengan memilih konsep utama sesuai dengan masalah yang ditelitiuntuk menyelesaikan masalahnya, dengan melalui pengurangan sampel, mempelajari kepustakaan yang mendukung konsep utama tersebut, dan memilihnya sehingga membentuk suatu konsep yang terpilih sebagai variabel intiuntuk menunjang teori yang akan dihasilkan.

\section{Validasi}

Validitas secara tradisional bukan merupakan konsekuensi pada metode GT. Ada empat prinsip yang harus dilihat, yaitu (Glaser \& Strauss, 1967, Glaser, 1978, Glaser, 1995). 
1. Kesesuaian/ 'Fit' yang dihubungkan sedekat mungkin dengan konsep yang dihasilkan sesuai dengan keadaan nyata. Hal tesebut dihubungkan dengan perbedaan yang konstan dari kejadian tersebut sesuai dengan teori atau konsep yang dihasilkan ('simultaneous/ constant comparability').

2. Relevansi/ 'relevance'. Relevansi dari riset dengan perhatian yang dapat dimengerti dan diperhatikan partisipan serta tidak hanya untuk kepentingan akademik.
3. Dapat diterapkan/ 'workability'. Teori dapat diterapkan ketika menjelaskan bagaimana masalah diselesaikan dengan berbagai variasi.

4. Dapat dimodifikasi/ 'modifiability'. Teori yang dapat dimodifikasi ketika data baru dibandingkan dengan data yang ada.

Grounded theory tidak pernah benar atau salah, tetapi lebih atau kurang sesuai, relevan, diterapkan, dan dimodifikasi. Pemilihan data disesuaikan dengan tujuan riset yang diuraikan sehingga hasil riset akan menjawab pertanyaan riset.

Skema 1. Tahapan Analisis Data

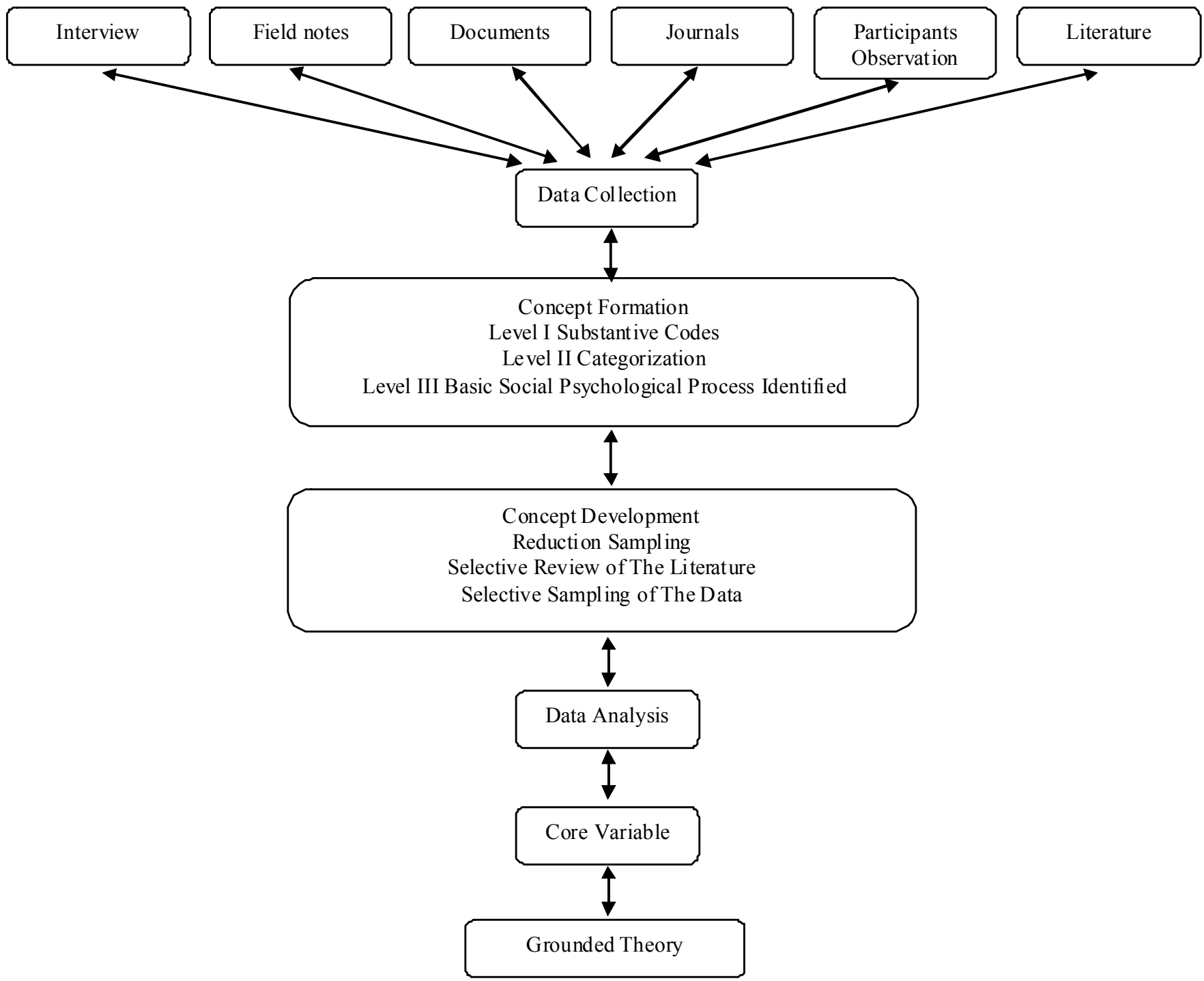

Sumber: Glaser (1994) 


\section{Kesimpulan}

Grounded theory merupakan metode riset kualitatif dengan analisis komparatif untuk menemukan teori dengan empat kriteria yang diterapkan yaitu berhubungan (dimengerti), cocok (valid), dan dapat dimodifikasi (dikendalikan). Data yang digunakan pada metode ini dapat diambil dari berbagai sumber data. Hasil dari grounded theory adalah pembentukan atau pengembangan teori atau konsep pada fenomena yang diteliti. Oleh karena itu, grounded theory sangat membantu perawat untuk memahami perilaku sosial sehingga perawat lebih mengerti dan memahami pasiennya (JH, ENT, HR)

\section{Referensi}

Allan, G. (2003). A critique of using grounded theory as a research method. Electronic Journal of Business Research Methods, 2 (1), pp 1-10.

Burawoy. (1991). Ethnography unbound power and resistance in the modern metropolis. Library of Congress Cataloging-in-Publication Data. Berkeley: University of California Press (pg. 8 27).

Chenitz, W. Carole, \& Swanson, J. M. (1986) From practice to grounded theory: Qualitative research in nursing. Englewood Cliffs: AddisonWesley.

Corbin, J \& Strauss, A. L. (2003). A grounded theory research. in fielding, $N$ (2003) (ed.) Interviewing (Volume 4). London: Sage.

Denzin, N. K. \& Lincoln, Y. S. (2000). Handbook of qualitative research (2nd ed.). Thousand Oaks: Sage Publications.

Field \& Morse, (1985). Nursing research: The application of qualitative approaches ( $2 \mathrm{nd} \mathrm{ed).}$ London: Chapan \& Hall.

Glaser, B.G. (1978). Theoretical sensitivity: Advances in the methodology of grounded theory. California: Sociology Press.

Glaser, B.G.. (1992). Basics of grounded theory analysis: Emergence vs forcing. California: Sociology Press.
Glaser, B.G. (ed). (1993). Examples of grounded theory: A reader. California: Sociology Press.

Glaser, B.G. (ed). (1994). More grounded theory methodology: A reader. California: Sociology Press.

Glaser, B.G. (ed). (1995). Grounded Theory 19841994. A Reader (two volumes). California: Sociology Press.

Glaser, B.G.., \& Strauss, A. L. (1967). The discovery of grounded theory. Strategies for qualitative research. Chicago: Adline Publishing Company.

Kelle, U. (2005). "Emergence" vs. "Forcing" of Empirical Data? ACrucial Problem of "Grounded Theory" Reconsidered. Forum Qualitative Sozialforschung/Forum: Qualitative Social Research [Online Journal], 6(2), Art.27, 49-50.

Legewie, H. \& Schervier-Legewie, B. (September 2004). "Forschung ist harte Arbeit, es ist immer ein Stück Leiden damit verbunden. Deshalb muss es auf der anderen Seite Spaß machen". Anselm Strauss interviewed by Heiner Legewie and Barbara Schervier-Legewie. Forum: Qualitative Social Research On-line Journal, 5 (3), Art. 22.

Martin, P. Y., \& Turner, B. A. (1986). Grounded Theory and Organizational Research. The Journal of Applied Behavioral Science, 22(2), 141.

Stein, M. (1985). Frontiers of stress research: stress and immunity. Stress in health and disease, $M$. R. Zales. New York: Brunner Mazel (pg. 97-114).

Schultz, P. R., \& Meleis, A. I. (1988). Nursing epistemology: Traditions, insights, questions. Journal of Nursing Scholarship, 20 (4), 217-221.

Strauss, A, \& Corbin, J. (1990). Basics of qualitative research: Grounded theory procedures and techniques. London: Sage.

Thomas, G., \& James, D. (2006). Re-inventing grounded theory: Some questions about theory, ground and discovery, British Educational Research Journal, 32 (6), 767-795.

Thorne. (1991). Key issues of training counsellors in W.Dryden and B. Thorne. Training in supervision for counselling in action. London: Sage. 